\title{
A autoridade através dos vestígios : a arqueologia na Missão Antropológica de Timor, 1953
}

The authority through the traces: the archeology in the Timor Anthropological mission, 1953

\section{Rita Juliana Soares Poloni}

\section{(2) OpenEdition}

\section{Journals}

Edição electrónica

URL: https://journals.openedition.org/aa/1944

DOI: 10.4000/aa.1944

ISSN: 2357-738X

\section{Editora}

Programa de Pós-Graduação em Antropologia Social (UnB)

\section{Edição impressa}

Data de publição: 1 dezembro 2017

Paginação: 109-132

ISSN: 0102-4302

\section{Refêrencia eletrónica}

Rita Juliana Soares Poloni, «A autoridade através dos vestígios : a arqueologia na Missão Antropológica de Timor, 1953», Anuário Antropológico [Online], v.42 n.2 | 2017, posto online no dia 12 junho 2018, consultado o 18 maio 2021. URL: http://journals.openedition.org/aa/1944 ; DOI: https:// doi.org/10.4000/aa.1944

\section{(c) $(1)(9)$}

Anuário Antropológico is licensed under a Creative Commons Atribuição-Uso Não-Comercial-Proibição de realização de Obras Derivadas 4.0 International. 


\title{
A autoridade através dos vestígios: a arqueologia na Missáo Antropológica de Timor, $1953^{1}$
}

\author{
Rita Juliana Soares Poloni \\ Universidade Federal de Pelotas
}

Este artigo discute as pesquisas arqueológicas desenvolvidas por António de Almeida e sua equipe durante a chamada Missão Antropológica de Timor (MAT), tendo como foco a primeira viagem científica desse projeto, datada de 1953. $\mathrm{O}$ artigo sugere que as pesquisas arqueológicas tiveram um lugar secundário, porém permanente, no conjunto da obra desta autointitulada missão. Isso porque, em primeiro lugar, a arqueologia era encarada como parte intrínseca da produção antropológica dos dois pesquisadores, como constituinte da definição epistemológica do campo. O conhecimento dos nativos passaria assim, de alguma forma, pelo conhecimento do seu passado através da arqueologia. Além disso, as pesquisas em pré-história, sobretudo, passariam a representar, com o passar dos anos, uma fonte cada vez maior de autoridade científica e status acadêmico, sobretudo em âmbito internacional e no que se refere às discussóes acerca da origem da humanidade.

Finalmente, o papel da arqueologia no projeto da MAT justifica-se no âmbito das estratégias de capitalização de autoridade científica e prestígio acadêmico e político prosseguidas pelos dois principais mentores da missão: os antropólogos António Mendes Correia e António de Almeida. Mendes Correia, assim como António de Almeida e outros cientistas do período, faz um percurso acadêmico que relaciona estudos iniciais na área da medicina com o desenvolvimento de pesquisas antropológicas, etnológicas e arqueológicas ao longo da vida profissional. Além disso, os dois cientistas manteráo outro ponto em comum: ambos unirão à carreira científica uma atuação significante na política. Mendes Correia foi presidente da câmara municipal do Porto e deputado à Assembleia Nacional entre 1945 e 1956, enquanto António de Almeida ocupou o cargo de deputado entre 1938 e 1957. O percurso científico e político da vida dos dois pesquisadores, e a sua inclinação para as pesquisas em contexto ultramarino, serão responsáveis por uma conformação muito peculiar das pesquisas antropológicas e arqueológicas no projeto das missóes. Primeiramente, os dois cientistas darão preferência às pesquisas no âmbito da antropologia física, quer por inclinaçáo das suas formaçóes acadêmicas, quer pela importância que o conhecimento direto do "indígena" representava para a manutençáo das colônias no período. Por 
conseguinte, como cientistas e como políticos, a visão de ambos no que toca à pesquisa em Timor seria estratégica, em termos, por um lado, de consolidaçáo e prestígio de suas carreiras profissionais e acadêmicas, em âmbito nacional e internacional; e, por outro lado, no que se refere aos interesses da própria naçáo em relação à manutenção e valorização dos territórios ultramarinos.

O projeto científico das missóes no que toca à sua componente arqueológica será, assim, compreendido comomeio através do qual a autoridade científica (em especial,aquela associada à figura de António de Almeida) é construída, consolidada e posta em questáo, servindo como iniciativa de reforço ou enfraquecimento do seu capital científico (Bourdieu, 1983).Para esse efeito, o texto descreve o contexto da primeira campanha da MAT e a forma como as investigaçóes foram desenvolvidas no terreno, com especial atenção ao sítio de Laga. Também discute a difusão das descobertas arqueológicas que marcaram aquela expedição e o seu esforço de internacionalização, ressaltando a importância dos congressos científicos e dos contatos com personalidades do universo arqueológico do período. No mesmo sentido, ressalta as reaçôes aos trabalhos científicos desenvolvidos, com destaque para as críticas de RuyCinatti. Por fim, compara as críticas ao trabalho arqueológico de António de Almeida com um panorama da produção arqueológica metropolitana no mesmo período.

\section{A estratégia político-científica para a arqueologia nas missóes}

Lançadas na década de 30 do século XX, as missões antropológicas às colónias portuguesas tiveram na figura do influente antropólogo portuense Mendes Correia o seu principal incentivador (Correia, 1934, 1936, 1941, 1945, 1947, 1951). Ao longo das décadas seguintes, as missōes permitiram o desenvolvimento de pesquisas nos territórios ultramarinos de Moçambique, Guiné, Angola e, finalmente, Timor, tendo como foco os estudos antropobiológicos de comunidades indígenas locais. Desde as primeiras discussôes, Mendes Correia procurou destacar os objetivos político-científicos do projeto que viria a ser denominado por "missóes antropológicas". Em 1936, Correia publicou o texto Pré-história de Moçambique: um plano de estudos,cuja pretensão era a de justificar a importância dos estudos arqueológicos na colônia que viria a ser o primeiro alvo do projeto das missóes. Neste texto, o autor justificava o desenvolvimento das pesquisas pelo atraso científico que Portugal apresentava em relação aos demais países europeus colonialistas, no que se refere ao conhecimento dos territórios africanos e de sua gente. Esse atraso era encarado como perigoso por tornar o país vulnerável às naçôes estrangeiras. Por outro lado, interesses nacionais também eram apontados, como o respeito aos antepassados que, de forma pioneira, iniciaram estudos nesse 
território, ou ainda a necessidade de defender e promover os próprios interesses materiais do Estado nesta colônia (Correia, 1936:28). É no contexto deste último ponto que a arqueologia surge defendida como um meio para conhecer as possibilidades dos povos através do seu passado e das suas origens:

a Arqueologia de Moçambique deve ser o objecto de estudo duma ou de algumas dessas missóes. O interesse de tal estudo não é meramente especulativo, embora, se o fosse, nem deixasse de merecer, por isso, a atençáo dum país civilizado. O conhecimento das possibilidades duma população reclama, porém, o estudo do seu passado, das suas origens (Correia, 1936:29).

Nessa medida, Correia aconselhava que investigaçóes fossem feitas em diversos campos da arqueologia, como as culturas líticas, as estações de arte rupestre, as exploraçóes de ruínas e a investigação de tradiçóes etnoarqueológicas (1936:29).

A conformação legal do projeto que se estabelecerá, em primeiro lugar, para Moçambique também demonstra o interesse dessa área do conhecimento na investigação ultramarina. O Decreto-lei 26.842, de 28 de julho de 1936, que institui a primeira das missões antropológicas, em agregação à já instituída Missão Geográfica de Moçambique, afirma serem os objetivos do projeto "proceder a estudos antropológicos e arqueológicos nas regióes em que actualmente trabalha aquela Missão" (Portugal, 1936).A partir de 1945, entretanto, o projeto das missóes antropológicas sofre algumas reformas, nomeadamente no que se refere ao papel da antropobiologia e da etnologia, que passam a confirmar-se como a prioridade desses projetos científicos, enquanto a arqueologia desaparece dos objetivos legais das missóes (Portugal, 1945).

A ampliação do número das colônias pesquisadas, por um lado, e a necessidade de lidar com recursos escassos, por outro, estreitam os interesses oficiais com os estudos que tivessem rápida e efetiva influência sobre o conhecimento dos indígenas dos territórios coloniais. Dessa forma, uma hierarquia de prioridades de pesquisa é estabelecida, colocando os estudos arqueológicos em último lugar na lista de interesses do governo ditatorial (Poloni, 2012;JMGIC, 1945).

Apesar disso, as campanhas desenvolvidas a partir dessa reforma para diversas colônias, entre elas Timor, continuam a manter as pesquisas arqueológicas entre as atividades científicas desenvolvidas pelo projeto. Elas podem ser identificadas nos projetos individuais de cada missão, nos relatórios dos trabalhos de campo realizados e, principalmente, na sua produção científica, fruto, muitas vezes, de participaçôes em congressos arqueológicos internacionais (Almeida, 1994b, 1994c, 1994d; Almeida\& França, 1960, 1964; Santos Júnior, 1950; Santos Júnior\& Santos, 1950). 
Assim, quando, em junho de 1953, António de Almeida apresentou ao presidente da Comissão Executiva da Junta de Investigaçóes do Ultramar um projeto para a realização de uma missão antropológica de Timor, deixou explícito que os trabalhos deveriam compreender "[...] investigaçóes antropológicas, etnográficas e pré-históricas nessa província”(Almeida, 1953).De fato, a arqueologia será uma presença substancial, sobretudo na primeira viagem científica da missão, que contará com a presença do próprio Mendes Correia e de Ruy Cinatti, outro importante antropólogo e agrônomo português do período, que na altura já se encontrava na província.

Numa série de textos publicada em 1955 no Boletim da Sociedade de Geografia de Lisboa, intitulada "Um mês em Timor", Mendes Correia recordaria assim as origens da primeira viagem da missão:

a Ciência, a Cultura, a Acção Moral e Espiritual, estão, ou devem estar, no primeiro plano das preocupaçóes nacionais em relação a Timor. [...] A saúde do corpo e da alma, a alimentação, a higiene, o ensino, todos os sectores da acção a desenvolver, estáo relacionados com o estudo científico da terra e da gente timorenses (Correia, 1955:175-176).

E, no mesmo texto, Mendes Correia apontaria a importância científica dos achados pré-históricos que seriam realizados nessa viagem:

também, com António de Almeida e Rui Cinatti, tive a alegria de encontrar jazidas líticas pré-históricas de que já demos conhecimento ao Congresso de Pré-história do Extremo Oriente, em Manila (Filipinas) e ao Congresso Internacional de Pré-história do ano passado em Madrid.[...]Os achados préhistóricos apóiam a tese da grande antiguidade do homem no arco indonésio, não apenas a $\mathrm{O}$., onde já há muito se registavam os achados de Java, mas também a E., onde não tinham sido encontrados testemunhos táo antigos, como os agora achados, da presença do homem. Autoridades científicas de alta categoria, como H. Breuil, reconheceram expressamente a antiguidade e valor das peças líticas encontradas(1955:179).

Percebe-se que as investigaçôes científicas, dentre elas a arqueológica, tinham um propósito de conhecimento da gente timorense e, embora consideradas menos práticas para o governo, continuariam a se desenvolver com a própria anuência das autoridades responsáveis. Mais: a importância da divulgação científica internacional dos achados timorenses e a sua inserção nas discussôes referentes à antiguidade do homem indonésio confirmavam a relevância relativa que a arqueologia parecia vir a assumir no projeto da MAT. Além disso, a concordância de Henri Breuil, prestigiado arqueólogo francês, acerca do valor dos artefatos 
encontrados confirmava que a produção no campo arqueológico se inseria dentro dos diálogos científicos internacionais, capazes de conferir aos investigadores envolvidos e ao país visibilidade e autoridade acadêmica.

Como se perceberá a seguir, será justamente esse o argumento de valorização e de polêmica da produçáo arqueológica da primeira viagem da MAT.

\section{A primeira campanha da Missáo Antropológica de Timor e o sítio de Laga}

A primeira viagem a Timor enquadrada pelo projeto da missão antropológica decorre de 27 de julho de 1953 a 31 de janeiro de 1954. A equipe chega a Díli em 2 de agosto, e a primeira referência à arqueologia aparece logo no dia seguinte. Nessa ocasião, como em outros momentos nos dias subsequentes, Almeida sairá em prospecção nas proximidades do local onde a equipe estava hospedada. O grupo estavaà espera do navio "Índia", que só fundearia no dia 11 de setembro, trazendo materiais para o início das atividades oficiais da missáo.

A narrativa desse primeiro encontro com a arqueologia foi-nos deixada pelo assistente António de Almeida Marques Júnior, cujos cadernos de campo foram preservados, junto a outros documentos da missão, no antigo Centro de Antropobiologia, chefiado por Almeida (Marques Júnior, 1953-1954). Sendo um diário cuidadoso, mas ao mesmo tempo pessoal, é possível dele extrair dados referentes ao desenvolvimento das pesquisas na colônia, assim como opinióes do autor acerca de assuntos diversos. No caso desses primeiros dias passados na província, o autor ressalta, por exemplo, em 6 de agosto: "informaram-nos hoje que o 'Índia' deve chegar a 27 do corrente, até lá continuaremos na boa vida”. E, no dia 11, repete: "ainda faltam 16 dias para a data provável de chegada do "Índia" e nós já nos vamos aborrecendo de nada se fazer”(Marques Júnior, 1953-1954).

Entretanto, além de realizar prospecçóes arqueológicas, a equipe visita algumas localidades e faz filmagens. Assim, o que parece implícito nesta afirmação é que as prospecções realizadas não pareciam fazer parte do que seriam, na sua opinião, as atribuições da missão. Tal situação indicia, logo à partida, a posição secundária da arqueologia nesse projeto.Os desenvolvimentos dos trabalhos da missão vêm a confirmar essa ideia inicial. Assim como em outras missóes antropológicas, os trabalhos em Timor se desenvolvem em torno das pesquisas em antropologia física, ficando a arqueologia sujeita a descobertas fortuitas no cumprimento dos trajetos determinados pelas pesquisas antropológicas.Entretanto, no caso desta viagem, alguns desenvolvimentos dão à arqueologia uma relevância especial nas atividades da missão. A presença de Mendes Correia e de Ruy Cinatti na equipe, durante o período inicial da campanha, além da incumbência, dada à Almeida, de participar 
de um congresso arqueológico internacional em meio aos trabalhos de campo, conferem uma dimensão particular às pesquisas arqueológicas ali desenvolvidas.

A chegada de Mendes Correia a Timor, no dia 23 de agosto,foi um acontecimento assinalável na rotina da missáo. Correia foi recebido no aeroporto pela equipe, incluindo Ruy Cinatti e António de Almeida, e pelo governador da Província. No dia 31, os três investigadores partem para uma missão ao interior, tendo retornado em 12 de setembro. Depois disso, toda a equipe parte para o interior, no dia 17, e no dia 19 de setembro Mendes Correia deixa Timor. Pouco se sabe, através do diário de Mendes Júnior, sobre as pesquisas realizadas pelos três investigadores na província. Contudo,uma das referências fornecidas pelo diário e confirmada por Mendes Correia no supracitado texto publicado no Boletim da Sociedade de Geografia,em 1955, é que foram encontrados sítios pré-históricos, em especial numa grande área que circundava a lagoa de Laga:

após o matabicho seguiu-se para Laga onde chegámos por volta das 9 horas. Como ali ainda haviam poucos indígenas para serem medidos, fomos para a lagoa "grasse-liu" (lagoa [liu] do sal [grasse]) onde já se encontravam uns homens à espera para se iniciarem as escavaçóes, visto os Srs. Profs. Mendes Corrêa e António de Almeida e o Engo. Rui Cinatti terem encontrado aqui material arqueológico[...]Pelas 15:30 h fomos de novo para a lagoa. Da vala 1 já tinham jocivado a terra.O terreno é constituído por uma camada de calhaus pequenos rolados, de mais de um palmo de altura e daí para baixo de terra argilosa também com alguns calhaus rolados.Da escolha pouco material em condiçóes deu. À superfície do terreno em quase toda a extensão ao longo da estrada até próximo do lago é que se encontrou bom material(Marques Júnior, 1953-1954).

Esta narrativa, datada de 24 de novembro de 1953, indica-nos que a descoberta do sítio foi feita anteriormente pelos três pesquisadores. Mas também demonstra o tratamento especial que mereceu, dada a sua dimensáo e aparente importância. Poucos sítios, em todas as missóes antropológicas, foram escavados, e tampouco tiveram trabalhadores contratados exclusivamente para esse trabalho. Por outro lado, a mesma narrativa do diário de Marques Júnior deixa claro que, enquanto o sítio era escavado pelos trabalhadores, a equipe principal da missáo prosseguia os seus trabalhos antropobiológicos na região. Isso quer dizer que, apesar de receber um tratamento importante, a escavaçáo do sítio náo passa a primeiro plano nas atividades dos pesquisadores, permanecendo subordinada às recolhas antropobiológicas. Além disso, os artefatos recolhidos no contexto da escavação são postos em posição secundáriaem relaçáo à recolha de superfície realizada no entorno do Lago. Novamente, nos dias 25 e 26 de novembro,confirma-se o mesmo quadro: 


\section{5 de Novembro}

[...]Almoçámos como ontem, em casa do Chefe do Posto, Victor Santa, também auxiliar da Missão e pelas 15:30 h fomos para a Lagoa.Uma vez aqui fui ver o material que tinham tirado das valas 2 e 3 que tinha dado ordem para abrirem, e que por sinal era pouco e fraco e depois continuei a pesquisa pela superfície do terreno, continuando a encontrar belas peças principalmente junto da estrada. Ao escurecer viemos embora, tendo deixado ordem para amanhã abrirem mais duas valas nos sítios por mim indicados.

26 de Novembro

[...]De tarde tornámos à Lagoa. Vi o material retirado das novas valas a no $4 \mathrm{e}$ 5 que escolhido pouco deu. Continuei a colheita, digo a pesquisa na direcção perpendicular à estrada até uma distância talvez de $500 \mathrm{~m}$ para Lautém, escolhendo ainda algum bom material.Em face das valas abertas pouco material ter dado e este na sua maioria fraco, resolvi terminarmos as escavações e prospecçóes até que o Sr. Dr. Almeida chegue(Marques Júnior, 1953-1954).

Dois aspectos chamam a nossa atenção nesses trechos. $\mathrm{O}$ primeiro refere-se à confirmação de que a maioria das peças extraídas do sítio de Laga foram fruto de recolhas de superfície e não de escavaçóes sistematizadas, de onde se pudesse concluir, com maior certeza, dados cronológicos ou culturais. As valas abertas, por exemplo, só foram fotografadas e medidas no dia 30 de novembro, quatro dias depois dos trabalhos serem abandonados.E em 19 de dezembro, mais de vinte dias depois do encerramento das atividades, o grupo retorna às valas abertas para retirar conchas fósseis do local e fazer mais recolhas de superfície no entorno da Lagoa. Percebe-se claramente que o contexto da escavaçáo não era uma prioridade nos trabalhos da equipa, e sim a recolha de artefatos esteticamente atrativos, denominados como"bom material" ou "belas peças".

A segunda informação importante fornecida pelo texto é que o próprio António de Almeida não estava presente quando do desenvolvimento desses trabalhos. Em realidade, havia partido para Díli no dia 4 de novembro a fim de participar do Congresso de Pré-história do Extremo Oriente, em Manila (Filipinas), apresentando dados recolhidos durante os trabalhos de campo ainda em curso em Timor, e em especial sobre o sítio de Laga. Esta participação no congresso será controversa, sendo alvo de críticas científicas e políticas, sobretudo, como veremos adiante, da parte de Ruy Cinatti. O aproveitamento desse evento pelos membros da missáo como reforço da sua autoridade científica, em consonância com os propósitos do próprio governo no congresso, e a forma como o trabalho científico é produzido ilustram claramente o sentido político da arqueologia no projeto da MAT. 


\section{O Congresso de Pré-história do Extremo Oriente: acordos e controvérsias}

Os trabalhos de campo da primeira campanha da MAT desenvolvem-se em meio ao recebimento de algumas notícias que vêm quebrar a rotina da equipe. No dia 24 de setembro, por exemplo, Almeida recebe um telefonema do governador da Província, comunicando-lhe que em Lisboa haviam proposto uma vez mais o seu nomepara deputado por Timor. Também ficam a saber que Mendes Correia havia recebido convite semelhante, da parte de Lisboa, antes de partir da província. Em 2 de novembro, com os trabalhos a se desenvolverem em Lospalos, Almeida recebeu novo telefonema do governador, conforme reportou Marques Júnior:

o Sr. Governador telefonou pela manhã ao Sr. Dr. Almeida informando-o de que tinha vindo um telegrama do Ministério nomeando-o Delegado da Metrópole ao Congresso a realizar agora em Novembro em Manila (Filipinas) e que o Engo. Agron. Rui Cinati iria representar Timor. Por esse motivo o Sr. Dr. Almeida deve partir para Díli no dia 4 para dizer umas larachas na sessão de propaganda eleitoral no dia 5 e partir depois no aviăo do dia 7 para Cupão (Marques Júnior, 1953-1954).

Com esta viagem, Almeida deixava a equipe em campo em Timor. A viagem teria, assim, duas razóes políticas. A primeira seria cumprir com o protocolo das eleiçóes ao cargo a que tinha sido indicado pouco mais de um mês antes. E a segunda seria aceitar a incumbência imposta pelo Governo Central de representar a Metrópole em um congresso internacional. Não se sabe até que ponto Almeida tinha conhecimento do fato, mas a sua participação no congresso havia sido proposta, em agosto, por Ruy Cinatti em carta enviada, desde Díli, para o presidente da Junta. Cinatti (1953) havia sido convidado a participar do congresso na área de ciências biológicas e agricultura e, ao pedir autorização para a sua viagem, também sugere a ida de Almeida:

tanto para o caso que me diz respeito - ciências biológicas e agricultura -como para os estudos que trouxeram o Exmo. Snr. Prof. Antonio de Almeida - ciências antropológicas - o Congresso da Ciência do Pacífico representa uma ocasião única de apresentar internacionalmente, o desconhecido Timor português, e de reinvindicar direitos que na atual ordem política se torna necessário defender.

Também não será possível avaliar até que ponto Cinatti se importava com as razóes especificamente políticas que aponta para justificar a sua ida, e a de Almeida, ao congresso, ou se as estava utilizando apenas como reforço argumentativo, para tornar imprenscindível a sua participação em um evento científico.Mas, sem dúvida, Cinatti tinha consciência de que tais questóes eram importantes para o Estado. 
Como pesquisador e político, Cinatti estava ciente da importância políticoestratégica da colônia e das missóes antropológicas. Em seu diário pessoal de 1954, narra uma conversa que tivera com o então governador de Timor, Fernando Alves Aldeia,acerca de várias questóes pessoais e políticas. Em tom provocativo, questiona uma entrevista que António de Almeida teria dado ao jornal Diário Popular, argumentando:

o senhor governador já leu as declaraçôes do Dr. António de Almeida no diário popular? Perante a afirmativa, dita quase em surdina, perguntei-lhe entáo se achava bem que fosse declarado publicamente ser quasi fim exclusivo de política externa a vinda da Missão Antropológica a Timor (Cinatti, 1954).

Muito embora não tenhamos mais detalhes sobre a referida entrevista de Almeida, fica claro que Cinatti tem noção da dimensão política e estratégica do projeto das missões na conservação das províncias ultramarinas e do impacto que informaçóes sobre a natureza do projeto poderiam ter para o governo, tanto em nível nacional como internacional. Também parece evidente que Cinatti sabe utilizar-se de tal argumentação segundo seus interesses, que neste caso referiamse à valorização do seu trabalho na província e a uma crítica contundente ao desempenho de Almeida como pesquisador, sobretudo no que se refere à primeira campanha da MAT.

Por outro lado, é notório o olhar crítico que Cinatti mantinha sobre as políticas coloniais e sobre os próprios colonos, sobretudo no que tange ao tratamento dado aos indígenas e ao patrimônio histórico e natural timorenses. Muito embora tais críticas não o tenham feito esmorecer do seu sentido patriótico em relação à província, que se negou a abandonar até o final de sua vida, por afeição ao país e aos indígenas de quem pensava ter se tornado irmáo por pacto de sangue, parece claro que Cinatti mantinha um olhar pouco entusiasta sobre o projeto políticocientífico para a colônia(Castelo,2011;Cinatti, 1954).

Assim, muito embora haja dúvidas acerca damotivação pessoal em estender o convite para o congresso de Manila para António de Almeida, está claro que Cinatti tinha perfeita noção da importância estratégica do evento para o país. Os conhecimentos científicos produzidos e a participaçáo no congresso teriam uma dupla importância: a inserção do país nas discussóes acerca da origem do homem "no arco indonésio", como referenciado por Mendes Correia, e uma confirmaçãodo domínio português sobre os seus territórios ultramarinos. Em outras palavras, o congresso seria ocasião para demonstrar poder e soberania colonial do país através de desenvolvimento científico. Com o envolvimento do país em debates acadêmicos internacionais, estava em jogo a sua inserção política 
em termos geoestratégicos regionais e "imperiais", em relação à sua possessão mais oriental. De fato, a descrição que Marques Júnior faz do retorno de Almeida à colônia, no dia 8 de dezembro, parece confirmar o sucesso do evento, percebido a partir do prisma político-científico:

pelas 13 horas chegou o Sr. Dr. Almeida, que vinha acompanhado do Sr. Administrador de Manatuto.Vinha entusiasmado pelo bom acolhimento no Congresso Científico do Pacífico da comunicação apresentada por ele sobre o material arqueológico de Laga, e mais satisfeito ficou quando lhe apresentei as peças por mim colhidas no mesmo local, que classificou de admiráveis(Marques Júnior, 1953-1954).

A julgar pelo entusiasmo de Almeida - bem como pela exaltação que Mendes Correia faria, tempos depois, das descobertas pré-históricas feitas em Timor -, seria de supor que o congresso e as pesquisas arqueológicas realizadasna colónia tivessem contribuído para aumentar a autoridade científica dos investigadores em contexto regional, tanto quanto para reforçar o país em termos de política internacional. Mas havia quem, na altura, pensasse de modo bem diferente. A descrição que Ruy Cinatti nos deixou deste episódio nos seus diários pessoais, referindo-se ao evento do qual também participou como representante de Timor, parece desmentir por completo essa versão optimista do "sucesso" da participação no congresso:

fartaram-se de dizer em Lisboa que a comunicação apresentada ao congresso de Manila era uma das melhores entre as quatrocentas e tantas... Eu só gostava de saber... porque afinal eu desconheço essa comunicação. A minha não é pois não a julgo a altura, ou com a categoria das que foram apresentadas no sub-comité de Botânica, por pessoas como o Dr. VanSteenis. A do Dr. António de Almeida, que também devia pertencer-me por ter assinado o resumo em conjunto com o prof. Mendes Correia não existe. [...] Quando se publicarem os 'Compte-rendus' aparecerá quando muito o resumo ligeiramente modificado e nada mais. [...] A comunicaçáo do doutor António de Almeida, chamemos-lhe assim, constou do resumo inicial e de mais uns acréscimos sobre o trabalho que a missão está realizando. Ora, isto não é nenhuma comunicação (Cinatti, 1954).

Esta descrição de Cinatti menciona uma discussão que ele tivera, em finais de abril de 1954, com o governador da Província, reproduzida no mesmo diário pessoal. A contenda teria sido principiada a propósito da compra de uma máquina, negada pelo administrador. $\mathrm{O}$ texto deixa claro, em trechos anteriores, que Cinatti tinha atritos com Almeida, de quem lamenta náo receber sequer uma correspondência ocasional. Também explicita o seu pouco apreço pelo governador, de quem afirma ter muito a perdoar.Entretanto, a descrição que Cinatti faz do 
conteúdo apresentado no congresso, pondo em questão o sucesso da comunicação apresentada, parece náo estar em total dissonância com o contexto dos trabalhos de terreno. Os trabalhos de campo estavam ainda em andamento na província, e as poucas escavaçóes feitas haviam ocorrido posteriormente à partida de Almeida para o congresso. Além disso, pouco tempo houve entre o momento em que recebeu a notícia de que participaria do congresso e a sua partida para Manila. Parece realmente pouco provável que os dados apresentados por Almeida no congresso pudessem ser muito aprofundados. Mas o relato crítico e cáustico que Cinatti fazia do que se passara no congresso ultrapassavaos reparos acerca do simples volume da informação:

Snr. Governador! Como V. Exa.deve compreender, não há na prehistória razōes oportunas que levem a ocultar factos científicos, a não ser a sua própria ignorância. Melhor seria entấo não comparticipar do congresso. A prehistória dessas regiôes é quasi desconhecida dos investigadores portugueses; e a nomenclatura muitas vezes diferente da que se usa na Europa. Se o snr. Governador assisti-se a uma reunião com alguns dos antropologistas de maior nomeada, como o Prof. Koenigswald e o Dr. Byer, veria a atrapalhação em que se encontrava o Dr. Antonio de Almeida. Ele mostrava um calhau, destes que levou de Timor, e classificava-o de "moustérien": é uma época da idade paleolítica. O prof. Koenigswald disse-lhe logo que não, pois para ser "moustérien" faltavam-lhe certas características. O Dr. António de Almeida, coitado, coçou a cabeça, disse "oui,oui", e confessou-me, em bom português, que já tinha metido água (Cinatti, 1954).

Nesta passagem, Cinatti afirma categoricamente que Almeida foi incapaz de contextualizar os artefatos que apresentou no congresso e que teria sido repreendido por autoridades científicas por causa disso. Ao mesmo tempo, ele próprio justifica o fato, esclarecendo que os contextos eram desconhecidos dos pesquisadores portugueses. Se levarmos em consideração que a equipe se encontrava em trabalho de campo na colônia, provavelmente o pouco conhecimento de Almeida sobre o sítio não estará, de todo, longe da realidade.

Tais observaçóes levam à confirmação de que a participação de Almeida no congresso de Manila, apesar da imaturidade das pesquisas na província, terá tido sentidos eminentemente políticos e que Almeida e Mendes Correia, com quem divide a autoria do texto arqueológico apresentado no congresso, terão sabido aproveitar esse evento para aumentar o seu prestígio acadêmico e a sua autoridade em contexto nacional. Cinatti confirma essa tendência quando ressalta a insistência de Almeida em falar sobre o pioneirismo das pesquisas portuguesas na região: 
quanto a história da prioridade dos portugueses na descoberta das estaçóes paleolíticas é uma outra história...[...] Como V. Exa. compreende, eu gostaria que fossem os portugueses a terem a prioridade, mas... o seu a seu dono. Ainda não vi para que serve toda essa propaganda, que mais parece de eleiçóes (Cinatti, 1954).

A questáo da prioridade das pesquisas teria certa importância acadêmica para Almeida, provavelmente, mas também era uma questáo política de Estado, uma questão de garantia dos direitos portugueses sobre as províncias, que o político Almeida não teria se furtado de ressaltar, assim como Cinatti também já havia feito, quando do pedido ao presidente da Junta.

Percebe-se, assim, um duplo motivador das pesquisas arqueológicas da missão. Deum lado, estavam questôes relacionadas ao incremento da autoridade científica dos pesquisadores e àcapacidade de fazer crer o seu sucesso acadêmico junto às autoridades responsáveis. De outro, questôes geoestratégicas dariam ao Estado, e também aos políticos-cientistas em questão, justificativas relativas para o prosseguimento das pesquisas, apesar da sua pouca utilidade prática na administração colonial.

Ao contrário das previsões pessimistas de Cinatti, as publicações de Almeida referentes ao sítio de Laga se realizaram. Segundo um de seus currículos, que reúne suas publicaçóes até meados da década de 1970. Almeida terá publicado duas versóes do texto escrito a seis mãos, sobre o sítio de Laga. A primeira delas seria Nouvelles Stations Lithiques du Timor Portugais et La Prehistoire de L'Indonesie Orientale (Correia, Almeida\& França, 1994), constante dos anais em língua francesa do congresso, e a segunda seria Preliminary notice of Paleolithic Station in Eastern Malaysian Archipelago (Portuguese Timor), que terá saído no ano seguinte, na versão em inglês dos mesmos anais (Correia, Almeida\& Cinatti, 1955).

$\mathrm{Na}$ versão francesa do texto, de pequenas dimensôes e republicada em $1994 \mathrm{em}$ um compêndio das obras de Almeida sobre temas orientais, poucas informaçóes são dadas acerca do contexto da descoberta do sítio, ao passo que o processo de classificação dos artefatos retirados merece atenção especial(Almeida, 1994a). O conjunto é dividido em três séries, tendo em vista sua classificação tecnológica e cultural (Tayaco-clacto-moustiéroide, Tayaco-moustiéro-clactonienne e moustiéroide, com elementos mais recentes).Ainda algumas dificuldades com o acesso ao material recolhido e transportado para a metrópole são destacadas, para justificar o andamento parcial das pesquisas. A conclusão do texto demonstra esperança de que o prosseguimento dos trabalhos investigativos na colônia pudesse trazer maiores esclarecimentos sobre a história humana na região, uma vez que descobertas paleontológicas como do Pitecantropus e do Homo soloensis, 
de Java, continuariam, até aquele momento, sem correspondências arqueológicas satisfatórias. Os estudos desenvolvidos na colônia permitiriam, assim, que o território timorense viesse a fornecer os primeiros testemunhos pré-históricos sobre o tema.

O texto em questão está carregado de significado político no que tange à importância presente e futura do objeto de estudo, e às implicâncias que a necessária continuidade dos estudos traria náo só para a arqueologia como para a história da humanidade. Por outro lado, a par de seu sentido político, o texto se esforça por estabelecer diálogo com a comunidade científica arqueológica, desenvolvendo um estudo classificatório e explicativo acerca dos artefatos líticos recolhidos em Laga.

Esses desenvolvimentos devem-se, como confirma Mendes Correia (1955) na sua publicação para Sociedade de Geografia, ao auxílio fulcral de Henri Breuil. O eminente arqueólogo, para além de seu extenso trabalho comparativo da arte parietal europeia, desenvolve muitos estudos no campo das indústrias líticas, utensilagem em osso e arte móvel pré-históricas, além dos contextos paleoambientais, desenvolvendo uma classificação referencial para o paleolítico superior europeu e métodos de dataçáo baseados na pátina e no desgaste dos materiais.

O arqueólogo francês também terá estado por diversas vezes em Portugal, investigando o tema da arte rupestre e das indústrias líticas e ministrando cursos sobre temas arqueológicos. Mesmo antes da sua primeira vinda ao país, em 1916, Breuil já mantinha correspondência com Leite de Vasconcellos, importante arqueólogo do século XIX e inícios do século XX em Portugal, estabelecendo, a partir de então, fortes relaçóes com os pesquisadores das geraçóes seguintes, tais como Mendes Correia, António de Almeida e Manuel Heleno e Georges Zbyszewski, mantendo redes de contato e configurando-se como referência científica para as pesquisas arqueológicas desenvolvidas em Portugal.

Mas Breuil também possuía experiência em pesquisas fora da Europa. Havia pesquisado em várias regióes de África e também na Ásia, com trabalhos na China, por exemplo. Mantinha também contato com grandes pesquisadores por todo o mundo, o que lhe permitia consultar coleçóes e ter uma visão bastante ampla dos temas pré-históricos nos seus mais diferentes contextos (Heleno, 1956; Raposo, 1993-1994).

Breuil passa, assim, a ser uma referência fundamental nos estudos do sítio arqueológico timorense.Todavia, suas opinióes acerca do material retirado de Laga, embora posteriores ao texto de Almeida, diferem em parte das que o pesquisador português apresenta acerca do sítio. Em carta de resposta enviada por Breuil a 
Mendes Correia, em março de 1957,o pesquisador francês descreve brevemente a cultura material encontrada no sítio de Laga, afirmando manter correspondência com António de Almeida acerca do mesmo tema:

a série antiga e principal é certamente de diversas idades, mas inteiramente bem anteriores aos tempos atuais. Ela pode, considerando o estado físico das peças, se dividir em três categorias visivelmente sucessivas, mas que se deslocam de uma para a outra e empregam a matéria uma da outra. Apesar de seus estados físicos serem diferentes, parece claro que uma parte das peças importantes chegou onde a encontramos depois de uma ou mais delocaçóes e elas demonstram um ou muitos locais de procedênciaanteriores. $\mathrm{O}$ sítio do Paleolítico antigo geograficamente menos distanciado de Timor e que pode se aproximar destas recolhas são de Sangiran e Java descobertas e estudadas pelo professor VonKoenigswald. ${ }^{2}$ Eu tive a ocasião de examinar diversas vezes as séries na Holanda, mas também em Singapura e me pareceram pertencer a diversos períodos; é o mais proximo depósito geográfico do paleolítico antigo que se pode comparar a Timor(Breuil, 1957).

Neste trecho, Breuil deixa transparecer aquilo que o diário de Marques Júnior confirma. As peças selecionadas do sítio, em contexto de recolhas de superfície, corresponderiam a diversas idades, alguns artefatos vindos, provavelmente, de outros sítios no entorno. Além disso, Breuil é cauteloso em relação à datação do sítio, apontando incerteza quanto à sua idade, muito embora as comparaçóes que estabelece com outros sítios da região façam crer que classificasse o sítio como paleolítico. Nota-se que Breuil cita as pesquisas de Koenigswald em Java, o mesmo cientista que Cinatti diz ter repreendido Almeida no Congresso de Manila.

Esses pontos são expostos de diferente maneira na citada publicação de Almeida, Correia e Cinatti, em francês:

o depósito é indiscutivelmente de morfologia paleolítica. O estabelecimento dessa cronologia atende definitivamente o aporte das amostras estratigráficas e faunísticas que nós consideramos por agora suficientes. Entretempos nos comprometemos a publicar o mais breve possível um compêndio de descrição de materiais e resultados compilados de pesquisas realizadas ou em processo de realização em curso a esse respeito. Não é difícil aceitar que a série III de Laga é mais recente que o paleolítico superior, mas consideramos arriscado a atribuição das séries I e II a uma data pos-pleistocênica[...]. As sondagens feitas em Laga nos forneceram, com uma fauna malacológica, algumas dezenas de peças líticas retocadas em profundidade numa escala entre meio metro e 1.20. Aguardemos, entretanto, os resultados de novas pesquisas(Correia, Almeida\& França, 1994). 
Almeida afirmacom maior certeza a datação paleolítica do sítio e, embora aponte dúvidas em relação às séries de artefatos apresentadas, deposita confiança no aprofundamento das pesquisas realizadas no período posterior à sua partida para o congresso. Ora, sabemos, a partir dos dados fornecidos pelo diáriode Almeida Júnior, que a forma como essas escavaçóes e coletas foram realizadas não permitiria o fornecimento de dados muito mais confiáveis sobre o sítio. $\mathrm{O}$ modocomo os dados disponíveis são transformados em discurso científico, utilizando a autoridade de Breuil para fortalecer a investigação realizada em Laga, dando-lhe maior confiabilidade e reforçando a autoridade dos investigadores portugueses, demonstra os sentidos políticos dessa atividade científica. A omissão de determinados aspectos do processo de pesquisa, ou de certas características do sítio, também se insere nesse contexto.

Por outro lado,a forma como as pesquisas arqueológicas são desenvolvidas em Timor, em 1953, no que se refere à precariedade em que a metodologia do trabalho de campo é empregada, não é uma exceção no universo das pesquisas desenvolvidas em território português, quer em contexto metropolitano, quer ultramarino, neste período. Antes, percebe-se que essas pesquisas inserem-se dentro do contexto teórico e histórico da produção arqueológica no país, impondo determinados horizontes à pesquisa.

\section{Vulnerabilidades da arqueologia portuguesa: entre Timor e o contexto metropolitano}

As críticas de Ruy Cinatti à produção arqueológica desenvolvida por António de Almeida no contexto da primeira campanha da MAT podem parecer, à primeira vista, uma confirmação do caráter excepcional das pesquisas. A dura análise de Cinatti parece dar a impressáo de que, em comparação com o trabalho desenvolvido por outros pesquisadores portugueses, em diferentes contextos, as pesquisas de Almeida teriam sido de caráter destacadamente inferior.Contudo, uma análise mais aprofundada das pesquisas arqueológicas desenvolvidas por outras autoridades nacionais, em contexto metropolitano, faz emergir um quadro que relativiza tais críticas. Tomando como exemplo duas obras arqueológicas publicadas no país na década de 60 do século XX, podemos ter uma breve noção das críticas formuladas por outros pesquisadores à forma como as investigaçóes se desenvolviam em contexto nacional. Tais críticas são particularmente interessantes, se tomarmos em conta as dificuldades acrescidas de realizar pesquisas em contexto ultramarino, comparadas aos recursos disponíveis na metrópole. 
O primeiro texto é da autoria de Abel Viana, arqueólogo de renome em contexto nacional, e intitula-se Algumas noçôes elementares de arqueologia prática. Datado de 1962, destaca a situação de precariedade das intervençôes no patrimônio arqueológico da Naçáo desde as suas primeiras pesquisas até o período da escrita da obra. Viana elogia Leite de Vasconcellos, ressaltando seu talento e a sua preparaçáo literária, científica e artística. Entretanto, ressalta que mesmo Vasconcellos, apesar de seu laborioso trabalho como fundador do museu que leva ainda hoje o seu nome, não teria disposto de investimentos para escavaçôes de grande vulto, aproveitando-se de achados fortuitos e de colecionadores particulares como fonte para o seu trabalho (Viana, 1962:70).

Muito embora Vasconcellos tivesse falecido no começo da década de 40 do século XX, o seu lugar como personalidade de vulto na história da arqueologia portuguesa nos indica um quadro a ser considerado. Ademais, as críticas de Viana à falta de trabalhos apurados de catalogação dos sítios arqueológicos nacionais, à sua constante destruição e à qualidade dos trabalhos realizados ainda em sua época demonstram que a superação dos problemas iniciais enfrentados por Vasconcellos não estava próxima do seu desfecho.

Outro exemplo da discussão do tema no país é um dos textos recomendados pelo próprio Viana na bibliografia da citada obra, denominado $A$ técnica alemã de escavaçôes arqueológicas e publicado em 1961 por Adriano Vasco Rodrigues,que é tão ou mais explícito no que tange às carências teórico-metodológicas da arqueologia em território nacional. Escrito como a descrição de um estágio realizado pelo autor naquele país,este trabalho tinha como propósito dar a conhecer as mais modernas técnicas de escavação arqueológica ali desenvolvidas. Acerca da comparação com o trabalho efetuado em Portugal, o autor declara que os alemães teriam um desagradável conceito daquilo que seria feito no país na altura. Segundo Rodrigues, eles "dizem que nós escavamos somente para encontrar paredes” (1961:9). E prossegue:

$\mathrm{Na}$ verdade nada têm de científicos os métodos que continuamos seguindo e não permitem um registo exacto, ou uma reconstituição segura dos interiores escavados. Por que nos limitamos, apenas, a retirar a terra dos interiores sem a interpretação científica dos mesmos, consideram-nos como pedreiros que se contentam em levantar muros sem encher os interiores... (Rodrigues, 1961:9).

O trecho é uma crítica contundente à ciência produzida em Portugal a partir do contato com outros métodos de trabalho e da percepção de que as pesquisas ali realizadas estavam aquém das discussôes e açóes implementadas no exterior. Mesmo mantendo a devida cautela em relação à opinião do autor, 
essa reflexão nos leva a considerar até que ponto a forma como os trabalhos de escavação em Laga foram conduzidos ultrapassa as especificidades das pesquisas ultramarinas e mergulha em procedimentos considerados corriqueiros nas pesquisas arqueológicas nacionais.

De fato, à luz do desenvolvimento do campo na atualidade, as pesquisas desenvolvidas pela missão são consideradas deficitárias em termos científicos. No que tange à qualidade do trabalho, terá sido a pesquisa de Ian Glover a merecedora de maior destaque no contexto anterior à invasáo indonésia. Ele terá efetuado sua pesquisa de doutoramento na regiáo, tendo realizado ali três campanhas de escavação, entre 1966 e 1967, no platô de Baucau e na regiáo de Tutuala, quando chegou a visitar sítios pesquisados por Almeida (Glover, 1969, 1970, 1972, 1973,1977, 1986;Oliveira, 2008: 12-19).As divergências acerca da idade do sítio de Laga retratam bem esse contexto de precariedade. Enquanto Almeida e Breuil acreditam na maior antiguidade do sítio, definido como musteriense de feições levalloienses (Paleolítico Médio), trabalhos de Glover e, novamente, de Koenigswald sugeririam que o mesmo sítio seria neolítico (Oliveira, 2008:13-14).

Essa divergência quanto à classificação do sítio expóe a precariedade dos trabalhos desenvolvidos no local, mas também algumas concepçóes préconcebidas do que esperavam ali encontrar. Acerca da precariedade desses estudos, Nuno Vasco Oliveira,arqueólogo português que nos últimos anos vem desenvolvendo importantes pesquisas nesse território, ressalta, por exemplo, que, muito embora as dataçóes de radiocarbono fossem um recurso disponível na época, Almeida nunca haverá tencionado usá-las para clarificar as cronologias criadas com base em tecnologia lítica. Almeida seria, assim, essencialmente um antropólogo (físico ou biológico) e seu interesse primordial nas missóes era realizar mediçôes antropobiológicas em grupos indígenas locais. Por outro lado, apesar do seu estudo multidisciplinar e, em alguns casos, bastante detalhado dos nativos, Almeida continuaria a manter um claro preconceito eurocêntrico em relação às suas capacidades, presumindo que a açáo civilizacional colonizadora dos povos timorenses seria um caminho inevitável (Oliveira, 2008:15-16).

Naturalmente, tais concepçóes eram partilhadas pelo Estado português do período e condicionaram o lugar das ciências sociais e, em especial, da arqueologia no interior do projeto de colonização científica ultramarina. Como já visto, a prioridade das missôes recaía sobre os trabalhos antropológicos, com o propósito de conhecer os grupos indígenas do território para melhor administrá-los. Percursos, tempos e recursos condicionavam as pesquisas arqueológicas a esses estudos prioritários. Mas, por outro lado, a manutenção dessas pesquisas, a despeito do pouco interesse estatal, ainda que realizados de forma bastante deficitária, pelo 
menos para os padróes atuais, indica que esta estava associada a discussões do próprio campo acadêmico em nível internacional e à sua consequente capacidade de fortalecer a autoridade científica dos pesquisadores envolvidos ou como ação estratégica do próprio Estado português colonialista em nível internacional.

\section{Consideraçóes finais}

Este artigo examinou a prática da arqueologia no contexto da primeira campanha da MAT, em 1953. Sugeriu-se que a arqueologia não integrou as atividades das missóes antropológicas unicamente por uma questáo de concorrência entre ideias científicas. A busca por prestígio ou autoridade dentro do campo bem como o atendimento de reivindicaçóes políticas de Estado caminharam lado a lado nesse contexto.Ao mesmo tempo em que foi considerado secundário na trajetória acadêmica e profissional dos investigadores envolvidos, e nos interesses governamentais em relação ao ultramar, o campo arqueológico persistiu como parte da produção científica do projeto de investigação ultramarina. Isso porque a sua permanência relacionava-se à importância das discussóes científicas que levantava, em âmbito internacional, aos contatos que possibilitava com personalidades do mundo acadêmico, à importância geoestratégica da contribuição portuguesa na região e como discurso político que possibilitava a manutenção do regime.

No caso da primeira viagem da missão a Timor, percebe-se que as pesquisas arqueológicas fazem parte desse projeto desde o seu planejamento. Mas a presença de Mendes Correia e de Ruy Cinatti em parte da viagem dá às investigaçóes arqueológicas, sobretudo à descoberta do sítio de Laga, uma dimensão especial para o campo no contexto do projeto. Enquanto Correia, assim como Almeida, utiliza a descoberta do sítio como uma forma de aumentar a sua autoridade científica e exaltar também o poder do Estado, Ruy Cinatti tem uma atitude ambígua em relação ao projeto. Em um primeiro momento, Cinatti foi o responsável direto pela participaçáo de Almeida no Congresso de Manila; posteriormente, porém, criticou a atuação do colega no evento. Se as críticas expressam atritos pessoais entre Cinatti e Almeida, também alertam para as condiçôes precárias em que as pesquisas apresentadas no congresso se desenvolveram, em consonância com os testemunhos apresentados no diário de campo do assistente da missão.

Por outro lado, sugeriu-se também neste artigo que náo devemos apreciar estas práticas de arqueologia colonial isoladamente do seu contexto metropolitano. As críticas à produção arqueológica em contexto metropolitano alertavam, igualmente, para um quadro geral que não se distanciava muito do que se passava em território timorense. Embora os métodos e técnicas adotados por Almeida pudessem ter sido outros, tendo em vista o desenvolvimento do campo 
em âmbito internacional no mesmo período, tudo leva a crer que o contexto ultramarino, com suas dificuldades específicas, somado a procedimentos já institucionalizados no país, resultaram em pesquisas que, embora deficitárias à luz da atualidade, não foram radicalmente discrepantes tendo em vista o quadro geral em que se inseriram.

Assim, percebe-se que, no caso aqui descrito, as pesquisas arqueológicas em contexto timorense derivaram parte substantiva do seu significado dos discursos políticos sobre ela e acerca dela produzidos, mais do que da sua contribuiçáo para o desenvolvimento das pesquisas científicas acerca da origem do homem indonésio (como os discursos de Almeida e de Correia queriam fazer crer). $\mathrm{O}$ reforço da autoridade científica desses pesquisadores deve ser entendido,dessa forma, dentro de uma estratégia política, na qual se cruzavam, de um lado, diálogos estabelecidos no interior do regime, fazendo coincidir a figura do político com a do cientista; e, de outro lado,a pesquisa em pré-história combinada com os interesses geoestratégicos do Estado português na manutenção dos seus territórios ultramarinos.

Recebido em 15/03/2017

Aprovado em 13/12/2017

Rita Juliana Poloni é bacharela e licenciada em história pela Universidade Federal do Espírito Santo (2003), mestra em teorias e métodos da arqueologia pela Universidade do Algarve (2007), pós-graduada em antropologia cultural pelo Instituto de Ciências Sociais da Universidade de Lisboa (2011), doutorada em história da arqueologia pela Universidade do Algarve (2012) e pós-doutorada em arqueologia pela Unicamp (2015). Atualmente, realiza pesquisa pós-doutoral no Programa de Pós-Graduação em Memória Social e Patrimônio Cultural da UFPel. Suas áreas de interesse incluem ciência colonial, ciência e fascismos, nacionalismos, etnogenealogias, etnoarqueologia, patrimônio, ditaduras e memórias traumáticas, tanto no contexto brasileiro quanto no português. 


\section{Notas}

1. Este artigo é um resultado do projeto As ciências da classificação antropológica em Timor Português (1894-1975), financiado pela Fundação para a Ciência e Tecnologia dePortugal (Ref. HC/0089/2009).

2. O professor Dr.Gustav Heinrich Ralph vonKoenigswald(1902-1982), uma das figuras eminentes dapaleoantropologia do século XX, foi um paleontólogo e geólogo que realizou pesquisas sobrehominídeos, com destaque para o Pithecanthropuserectus. Suas pesquisas em Java, particularmente em Sangiran, levaram-no a afirmar que os vestígios ali encontrados correspondiam aostrês níveis do Pleistoceno(Franzen, 1983; Tobias, 1984). Nota-se, em relação ao contexto timorense em debate, que as pesquisas de Koenigswald apontam no sentido de uma grande antiguidade da ocupação humana na região indonésica, corroborando os interesses científicos de Almeida acerca do sítio de Laga.

\section{Referências}

ALMEIDA, António de.1953. Projecto enviado por António de Almeida ao presidente da Comissão Executiva da Junta de Investigações do Ultramar, em 16 de junho de 1953. Lisboa: Instituto de Investigação Científica Tropical, Departamento de Ciências Humanas, Espólio das Missōes Antropológicas, Processo 150.

. 1994a. O oriente de expressão portuguesa. Lisboa: Fundação Oriente.

. 1994b. "IV Congresso de Pré-história do Extremo Oriente. Separata de Garcia de Orta, Revista da Junta das Missóes Geográficas e de Investigaçóes do Ultramar, Vol II, n³, [19--]”. In: António de Almeida. O oriente de expressão portuguesa. Lisboa: Fundação Oriente. pp. 349-357

. 1994c. "A contribution to the study of the prehistory of Portuguese Timor: lithic industries. Archaeology at Eleventh Pacific Science Congress, no 1, Hawaii, 1967". In: António de Almeida. O oriente de expressão portuguesa. Lisboa: Fundação Oriente. pp. 55-67.

1994d. "Da pré-história do timor português: pinturas rupestres: memórias da Academia das Ciências de Lisboa. Tomo XIX, Lisboa, 1976”. In: António de Almeida. O oriente de expressão portuguesa. Lisboa: Fundação Oriente.pp.. 27-49.

ALMEIDA, António de \& FRANÇA, J. Camarate. 1960. "Recintos muralhados de Angola”. In:FRANÇA, J. Camarate; ALMEIDA, António de.Estudos sobre pré-história do ultramar português, $n^{\circ} 16$. Lisboa: Memórias da Junta de Investigaçóes do Ultramar. pp. 107-124 
ALMEIDA, António de \& FRANÇA, J. Camarate. 1964. "Notícia sobre o Paleolítico do território de Cabinda (Angola)". In: JUNTA DE INVESTIGAÇÓESS DO ULTRAMAR. .Estudos sobre pré-história do ultramar português, n 50, volume 2. Lisboa: Memórias da Junta de Investigaçóes do Ultramar. pp. 101-112

BOURDIEU, Pierre. 1983. "O campo científico". In: Renato Ortiz (org.). Pierre Bourdieu: sociologia. São Paulo: Ática. pp. 122-155

BREUIL, Henri. 1957. Carta enviada por Henri Breuil a António de Almeida em março de 1957. Biblioteca do Museu de Paris, arquivo digital de documentos acerca de Timor Colonial do projeto "As ciências da classificação antropológica em "Timor Português" (1894-1975).

CASTELO, Cláudia. 2011. "Ruy Cinatti: poeta, 'agrónomo e etnólogo', instigador de pesquisas em Timor".Atas do Colóquio Timor: missóes científicas e antropologia colonial. AHU, 24-25 de maio de 2011. pp. 1-16.

CINATTI, Ruy. 1953. Correspondência enviada por Ruy Cinatti ao presidente da Junta das Missóes Geográficas e de Investigação do Ultramar, em 28 de agosto de 1953. Lisboa: Instituto de Investigaçáo Científica Tropical, Departamento de Ciências Humanas, Espólio das Missões Antropológicas, Processo 273.

- 1954. Diário pessoal:espólio Ruy Cinatti. Lisboa: Universidade Católica Portuguesa.

CORREIA, António A. Mendes. 1934. Discurso inaugural no I Congresso Nacional de Antropologia Colonial: extracto das Actas do Congresso. Porto: Ediçóes da $1^{\circ}$ Exposição Colonial Portuguesa.

Portuguesa.

1936.Pré-história de Moçambique: um plano de estudos. Porto: Imprensa

1941. Plano de estudos antropológicos coloniais, criado por indicação da Junta de Missóes Geográficas e de Investigaçóes Coloniais, por Mendes Correia, director do Instituto de Antropologia da Universidade do Porto em 12 de março de 1941. Lisboa: Instituto de Investigação Científica Tropical, Departamento de Ciências Humanas, Espólio das Missóes Antropológicas, Processo 150.

. 1945. "Missões antropológicas às colónias". Jornal do Médico, VII(149):11-12.

. 1947. Uma jornada cientifica na Guiné Portuguesa. Lisboa: Agência Geral das

Colónias.

1951. Investigação científica no ultramar: extracto do fascículo I do Tomo XXXV dos Anais da Faculdade de Ciências do Porto. Porto: Imprensa Portuguesa. 
CORREIA, António A. Mendes. 1955. "Um mês em Timor:palestras na Emissora Nacional, na série A Ciência ao Serviço da Humanidade, 26 fev., 5, 12 e 26 de março e 2 e 9 de abril de 1955". Boletim da SGL, 73(4-6):173-191.

CORREIA, A. A. Mendes; ALMEIDA, António de\& CINATTI, Ruy. 1955. "Preliminary notice of a Palaeolithic station in the eastern Malaysian Archipelago (Portuguese Timor)". Abstracts and Messages of the 4th Far Eastern Prehistory Congress and Anthropology Division of the 8th Pacific Science Congress, Quezon City, Philippines, pp. 52-53.

CORREIA, António Mendes; ALMEIDA, António de\& FRANÇA, Camarate. 1994."Nouvelles stations lithiques du Timor Portugais et la préhistoire de l'Indonésie orientale: crónica del IV Congresso Internacional de Ciências Préhistóricas y Protohistóricas, Saragoza, 1954.” In: António de Almeida. O oriente de expressão portuguesa. Lisboa: Fundação Oriente. pp. 295-298.

FRANZEN, Jens Lorenz. 1983. "In Memoriam Gustav Heinrich Ralph von Koenigswald 1902-1982”. Senckenbergianalethaea, 64:381-402.

GLOVER, Ian.1969. "Radiocarbon dates from Portuguese Timor". Archaeology and Physical Anthropology in Oceania, 4:107-112.

.1970. "Pleistocene flaked stone tools from Timor and Flores". Mankind, 7:188-190.

1972. Excavations in Timor: a study of economic change and cultural continuity in prehistory. Canberra: Australian National University.

.1973. "Island South east Asia and the Settlement of Australia". In:D. E. Strong (ed.).Archaeological theory and practice. London: Seminar Press. pp. 105-129.

.1977. "The Late Stone Age in Eastern Indonesia". World Archaeology, 9:42-61.

1986. Archaeology in Eastern Timor,1966-67. Canberra: RSPAS, Australian National University.

HELENO, Manuel. 1956. "O professor Henri Breuil". O archeologo português, 3(nova série):239-246.

JUNTA DAS MISSÕES GEOGRÁFICAS E DE INVESTIGAÇÓES COLONIAIS (JMGIC).1945. Ocupação cientifica do ultramar português: plano elaborado pela Junta das Missóes Geográficas e de Investigaçôes Coloniais e parecer do Conselho do Império Colonial. Lisboa: Divisão de Publicações e Biblioteca, Agência Geral das Colónias. 
MARQUES JÚNIOR, António de Almeida. 1953-1954. Caderno de campo relativo aos trabalhos da primeira campanha da Missão Antropológica de Timor. Lisboa: Instituto de Investigação Científica Tropical, Departamento de Ciências Humanas, Espólio das Missóes Antropológicas.

OLIVEIRA, NunoV.2008. Subsistence archaeobotany: food production and the agricultural transition in East Timor. Tese de doutorado, Australian National University.

POLONI, Rita J. S. 2012. Expediçöes arqueológicas nos territórios de ultramar: uma visäo da ciência e da sociedade portuguesa do periodo colonial. Tese de doutorado, Universidade do Algarve.

PORTUGAL. 1936. Decreto-lei 26.842, de 28 de julho de 1936. Diário do Governo, 10 série, no 175.

. Decreto-lei 34.478, de 3 de abril de 1945. Diário do Governo, $1^{\circ}$ série, nº 70.

RAPOSO, Luis. 1993-1994. "Do Somme ao Tejo: a vida e obra de Henri Breuil e sua contribuição para a pré-história portuguesa”. O Arqueólogo Português, IV(11/12): 223-290.

RODRIGUES, Adriano Vasco. 1961. A técnica alemã de escavação arqueológica. Separata de Lucerna. Porto: Marânus, v. I, no 3-4.

SANTOS JÚNIOR, J.R.R. 1950. "Carta da pré-história de Moçambique”. XIII Congresso Luso-Espanhol para o Progresso das Ciências, separata do tomo V, 4a secção, Ciências Naturais.

SANTOS JUNIOR, J. Norberto\& SANTOS, Luis. 1950. "Nota sobre o 'Muzimo' do abrigo com pinturas rupestres da Mavita”. XIII Congresso Luso-Espanhol para o Progresso das Ciências,separata do tomo V, 4a secção, Ciências Naturais.

TOBIAS, Phillip V. 1984. "The life and work of professor dr. G. H. R. von Koenigswald”. AufsaetzeundRedenderSenckenbergischenNaturforschendenGesellschaft, 34:25-96.

VIANA, Abel. 1962. Algumas noçóes elementares de arqueologia prática. Beja: Carlos Marques. 


\section{Resumo}

Tendo como objeto de estudo a primeira viagem da Missão Antropológica de Timor (1953), buscar-se-á perceber qual o papel ocupado pela arqueologia em viagens científicas promovidas pelo Estado colonial e protagonizada por cientistas nacionais, cujos interesses políticos, estratégicos e científicos se entrecruzam. A manutenção das pesquisas relacionadas ao campo em questão revela-se como fruto de açóes com motivações diversas que, se por um lado evidenciam o papel secundário da arqueologia, por outro justificam a sua permanência nesses empreendimentos. No caso da viagem em questão, a arqueologia toma um papel destacado entre as pesquisas realizadas, permitindo uma análise pormenorizada do seu papel no universo dos interesses que circunscrevem o período em que as missóes antropológicas se desenvolveram.

Palavras-chave: arqueologia, antropologia, colonialismo, Portugal, Timor-Leste.

\section{Abstract}

This article seeks to understand the role of archeology in scientific missions promoted by the Portuguese colonial state and carried out by national scientists, at the intersection of political, strategic and scientific interests. It draws on the case of the Timor Anthropological Mission in 1953 to suggest that the development of research in this field was a result of actions with diverse motivations. On the one hand, the analysis of these motivations reveals the secondary role of archeology in this field expedition; on the other hand, it reveals how archaeological research was justified and maintained in the course of this mission. In the case of this field trip, archaeology played a prominent role in the Portuguese anthropologists' researches, allowing for a detailed analysis of its place in wider scientific and political interests concerning the period in which the anthropological missions developed.

Keywords: archaeology, anthropology, colonialism, Portugal, East Timor. 